Comparison of six jet nebulising systems for the nebulisation of rhDNase $(2.5 \mathrm{mg}$ in $2.5 \mathrm{ml})$

\begin{tabular}{|c|c|c|c|c|c|}
\hline \multirow[b]{2}{*}{$\begin{array}{l}\text { Compressor } \\
+ \\
\text { Nebuliser }\end{array}$} & \multicolumn{2}{|c|}{ Recommended systems } & \multicolumn{3}{|c|}{$R M C H$ systems } \\
\hline & $\begin{array}{l}\text { Pulmo-aid } \\
+ \\
\text { Updraft }\end{array}$ & $\begin{array}{l}\text { CR5O } \\
+ \\
\text { Sidestream }\end{array}$ & $\begin{array}{l}\text { CR60 } \\
+ \\
\text { Sidestream }\end{array}$ & $\begin{array}{l}\text { CR60 } \\
+ \\
\text { MicroNeb III }\end{array}$ & $\begin{array}{l}\text { Turboneb } \\
+ \\
\text { MicroNeb III }\end{array}$ \\
\hline \multirow{2}{*}{$\begin{array}{l}\text { Median mean diameter }(\mu \mathrm{m}) \\
\text { Nebulisation time }(\mathrm{min}) \\
\text { Residual volume }(\mathrm{ml}) \\
\% \text { Of activity in the released } \\
\text { aerosols }{ }^{\star}\end{array}$} & $\begin{array}{l}5 \cdot 19 \\
6 \cdot 57 \\
0 \cdot 5\end{array}$ & $\begin{array}{l}5 \cdot 23 \\
2 \cdot 9 \\
0 \cdot 6\end{array}$ & $\begin{array}{l}3 \cdot 83 \\
3 \cdot 85 \\
0 \cdot 4\end{array}$ & $\begin{array}{l}4 \cdot 89 \\
6 \cdot 83 \\
0 \cdot 6\end{array}$ & $\begin{array}{l}4 \cdot 87 \\
5 \cdot 88 \\
0 \cdot 7\end{array}$ \\
\hline & 73 & 71 & 65 & 64 & 65 \\
\hline
\end{tabular}

RMCH = Royal Manchester Children's Hospital

ॠThe activity of $2.5 \mathrm{mg}$ (in $2.5 \mathrm{ml}$ ) rhDNase is taken as $100 \%$.

Further efficacy trials are urgently required to evaluate the dose-response relationship of rhDNase when it is delivered by different nebulising systems.

J C C HUNG G HAMBLETON M SUPER Royal Manchester Children's Hospital, Hospital Road, Pendlebury, Manchester M27 4HA

1 Ranasinha C, Assoufi B, Shak S, et al. Efficacy and safety of short-term administration of and safety of short-term administration of aerosolised recombinant human DNase I in
adults with stable stage cystic fibrosis. Lancet adults with stable st
1993; 342: 199-202.

2 Kunitz M. Crystalline desoxyribonuclease 1. Isolation and general properties: spectrophotometric method for the measurement of desoxyribonuclease activity. F Gen Physiol 1950; 33: 349-62.

3 Everard ML, Clark AR, Milner AD. Drug delivery from jet nebulisers. Arch Dis Child 1992; 67: 586-91.

4 Shah PL, Scott SF, Hodson ME. Report on a multicentre study using aerosolised recombinant human DNase I in the treatment of cystic nant human DNase $I$ in the treatment of cystic
fibrosis patients with severe pulmonary disease. fibrosis patients with severe pulmonary
Pediatr Pulmonal Suppl 1993; 9: 157-8.

5 Newman SP, Woodman G, Clarke SW. Deposition of carbenicillin aerosols in cystic fibrosis: effects of nebuliser system and breathing pattern. Thorax 1988; 43: 318-22.

\section{Adverse events occurring during interhospital transfer of the critically ill}

EDITOR,-The study by Barry and Ralston is extremely important in highlighting the dangers associated with transport of critically ill children by non-specialised personnel. ${ }^{1}$ The fact that $75 \%$ of their patients suffered from serious clinical complications during transfer by non-specialised teams is both alarming and unacceptable. It is indeed very unfortunate that in spite of recent recommendations some critically ill children in the UK are still being transferred by non-specialised teams. A recent study from the US has shown that the use of specialised paediatric retrieval teams reduces the morbidity of interhospital transport. ${ }^{2}$

We have recently completed a study (in preparation for publication) looking at the morbidity associated with the transfer of 51 critically ill children by our specialised paediatric intensive care retrieval team. Morbidity during transport was assessed in terms of physiological deterioration and equipment related adverse events using the criteria described by Kanter and Tompkins. ${ }^{3}$ Only two $(3.9 \%)$ patients had possibly preventable deterioration (episodes of apnoea and oxygen desaturation in one patient and hypoglycaemia in the other) during transport and there were no instances of equipment related adverse events. Severity of illness in our patients, as measured by the median (range) PRISM score on admission at the referring hospital decreased from $14(1-45)$ to $8(0-23)$ on arrival at our paediatric intensive care unit.

Our study suggests that a specialised paediatric retrieval team can not only institute intensive care on arrival at the referring hospital, but also transport the patient back to a tertiary centre with an improvement in the severity of illness and minimal morbidity, demonstrating that similar unequivocal results can be achieved here in the UK. These results should strengthen the case for specialised paediatric retrieval even further.

A regional specialised paediatric intensive care retrieval service catering to meet all the demands of the region would seem the ideal solution for the future. For the present, however, tertiary centre intensive care units that accept critically ill children should try and extend the benefits of paediatric intensive care to the child awaiting transfer by sending out specialised retrieval teams to the referring hospital, thereby initiating intensive care earlier and decreasing the morbidity associated with non-specialised retrieval.

$$
\begin{array}{r}
\text { JOSEPH BRITTO } \\
\text { SIMON NADEL } \\
\text { PARVIZ HABIBI } \\
\text { MICHAEL LEVIN } \\
\text { Paediatric Intensive Care Unit, } \\
\text { Department of Paediatrics, } \\
\text { St Mary's Hospital Medical School, } \\
\text { London W2 INY }
\end{array}
$$

1 Barry PW, Ralston C. Adverse events occurring during inter hospital transfer of the critically ill. Arch Dis Child 1994;

2 Edge WE, Kanter RK, Weigle CGM, et al. Reduction of morbidity in interhospital transport by specialised pediatric staff. Crit Care Med 1994; 22: 1186-91.

3 Kanter RK, Tompkins JM. Adverse events during interhospital transport: physiological deterioration associated with pretransport severity of illness. Pediatrics 1989; 84: 43-8.

\section{Patterns of scald injuries}

EDITOR,-Yeoh et al found only four children with non-accidental scalds out of a total of 68 bath scald injuries treated in a burns unit in 2.5 years. ${ }^{1}$ The authors rightly draw attention to the unacceptably hot and in some cases dangerous temperatures in many household hot water systems. However in this country fewer cases of abuse are recognised than in the USA where there have been more studies. Tennant and Davison did not find a single case of non-accidental bath scald injury in 91 cases, although $60 \%$ were aged 2 years or less. $^{2}$

Why should experience in Cardiff and Edinburgh be so different to cities in the USA?

In the USA estimates vary from $10-25 \%$ of burns being deliberately inflicted by adults. ${ }^{3}$ In one study of 71 inflicted burns the most frequent cause of injury were scalds (83\% tap water) which involved buttocks, perineum, feet (or foot), hands (or hand) in various combinations. ${ }^{3}$ In contrast, genuinely accidental scald injuries are more often due to cause other than tap water $(15 \cdot 7 \%)$. Studies have emphasised the young age in abuse with many below 3 years.

Many children with abusive burns and scalds will not in our experience have other injuries such as bruises or fractures (only $\left.19 \cdot 7 \%{ }^{3}\right)$. The diagnosis will depend on a high index of suspicion (abuse until proved otherwise) and an awareness that adults do understand the burning hazard associated with hot tap water. Such scalds should not be excused by a purported lack of knowledge. This observation is supported by the virtual absence of accidental tap water burns in non-impaired adults. ${ }^{4}$

Paediatricians must be aware of the features associated with deliberate immer sion. Careful consideration of the history including analysis of scald pattern in relation to child's development (ability to get into the bath, etc) and a knowledge of the detailed environment and parental behaviour at the time the injury was sustained are needed. Paediatricians should develop protocols and systems for the investigation of tap water scald injuries as few will be compatible with acceptable child care practice but involve either deliberate injury or neglect. Parent education and manipulation of water temperature are unlikely to be sufficient protection for these vulnerable children. At present too few cases are being recognised and reported.

$$
\begin{array}{r}
\text { C J HOBBS } \\
\text { J M WYNNE } \\
\text { St Fames's University Hospital, } \\
\text { Leeds LS9 } 7 T F
\end{array}
$$

1 Yeoh C, Nixon JW, Dickson W, Kemp A, Sibert JR. Patterns of scald injuries. Arch Dis Child 1994; 71: 156-8

2 Tennant WG, Davison PM. Bath scalds in children in the south-east of Scotland. $\mathcal{F} R \mathrm{Coll}$ Surg Edinb 1991; 36: 319-22.

3 Purdue GF, Hunt JL, Prescott PR. Child abuse by burning - an index of suspicion. 7 Trauma 1988; 28: $221-4$

4 Purdue GF, Hunt JL. Burn injuries. In: Ludwig $\mathrm{S}$, Kornberg AE, eds. Child abuse, a medical $\mathrm{S}$, Kornberg AE, eds. Child abuse, a medical
reference. 2nd Ed. New York: Churchill reference. 2nd Ed.
Livingstone, 1992.

Attitudes and beliefs of Muslim mothers towards pregnancy and infancy

EDITOR,-The article by Gatrad on attitudes and beliefs of Muslin mothers towards pregnancy and infancy is timely and appropriate. ${ }^{1}$ However as a practising Muslim paediatrician I found his article intriguing because he seems to mix and confuse Muslim and cultural beliefs with each other.

Although in some cultures pregnant women continue to fast during the fasting month of Ramadan, religiously it is discouraged. The practice of giving honey to the baby or tying a string around the baby's neck or wrist are both entirely cultural and have no religious basis whatsoever. Similarly the use of a mixture of herbs and nuts cooked in wheat and purified butter during the postnatal period is very much part of Indian culture and is not seen in many other Muslim parts of the world, for example Arabia. Gatrad goes on to quote other cultural issues and confuses them with Islam, for example 